\title{
Urban tourism: designing a tourism space in a city context for social sustainability
}

\author{
N. Giriwati, R. Homma \& K. Iki \\ Department of Architecture and Environmental Planning, \\ Kumamoto University, Japan
}

\begin{abstract}
A town, city or urban region has a potential which stems from its own natural form, sense of place, sense of history, spirit and ethos. Nowadays, in addition to the primary demands of life, many urban areas are facing an increasing population and a growing demand or expectation of the city for tourism activity. However, whilst increasing tourism activity is an important economic backbone for certain cities, tourism facilities are responsible for a substantial increase in environment degradation due to tourists' rising expectation for services and facilities. The structure of this research is first to present the general overview of urban tourism in Kumamoto City through literature. This study will analyze the potentials of Kumamoto City in the creation of urban tourism, with case studies of other cities, to meet the need of integrative urban planning. The aim of this research is to review and evaluate the importance and influence of sustainability of the city through the view of making a tourism space for people. This analysis seeks to illustrate the phenomenon of urban tourism in the scale of a Japanese city. The conclusion discusses the importance of urban tourism in proposing social sustainability, and the potential for development in the current conditions. Keywords: urban tourism, city spaces, social sustainability.
\end{abstract}

\section{Introduction}

The rapid growth of tourism has become an important economic backbone for certain cities. The World of Tourism Organization (1997, 2001, 2006a) forecasts that international arrivals will reach nearly 1.6 billion by the year 2020 [1]. The growth of the tourism industry describes the high potential of tourism and its economic impacts as very beneficial to a city. Tourism is the world's largest 
industry because the tourism industry provides enormous job opportunities and generates huge profits into a destination. Because of this fact, we need to consider tourism growth during the urban planning and design stage in providing opportunity for the growth of the tourism industry as another source of economic income.

Nowadays, many urban areas are increasing in population and demands; expectations of the city and also leisure, in addition to the primary demands of life. There is increasing in tourism and travel activity that creates the interregional and domestic tourist, resulting in competition between cities in the world. Also, different urban areas that face competition from a wide range of destinations for tourist's investment or money that have needed to improve tourism facilities. The tourist characteristic is changing very quickly; different expectations are generated and creating a new image of an area becomes the challenge of planning and management of a city as a tourist destination. As various kinds of tourist expectations such as travel for convention purposes or learning about other cultures or travel for business develop, it becomes necessary to consider how to expand the specific elements of urban tourism that determine the attractiveness of the city for visitors.

\section{Tourism and urban space}

\subsection{The context of the urban environment for tourism}

The urban environment offers social, cultural, physical and aesthetic aspects where tourist activity can exist. This urban form shapes experiences as visitors can interact with attractions and the infrastructure can be generally developed for non-tourism purposes, local residents and economic activity.

Every town, city or urban region whatever its inherent natural characteristics of site and terrain and man-made problems has a potential which stems from its own natural form, sense of place, sense of history, spirit and ethos [2]. People perceive a city in different ways and each city has a public image which is an overlap of many individual images. Imageability in a city may be said to be more a perceptual concept than a physical or visual entity. It is the interpretation of various layers of a city's images, its form, profile and experiences over a period of time. Imageability refers to the probability that an environment will evoke a strong image from observers [3]. Different cities have different kinds of images. Some cities are known as industrial cities; some as metropolitan cities and the others as tourism cities.

The urban area is one kind of destination for tourists. The destination is for secondary home owners, walkers, and hunters where the tourist it first and foremost a consumer of places and any place capable of satisfying the tourist's need for relaxation, for example, must be a destination. The other definition is the destination is a total tourism product that is a combination of resources and services. Resources continue the initial attraction that the destination has for visitors, while services are provided to make possible or enhance the visit, and 
are provided mainly or entirely for tourists [4]. The spatial concept of tourism destination and component is shown in figure 1 [5].

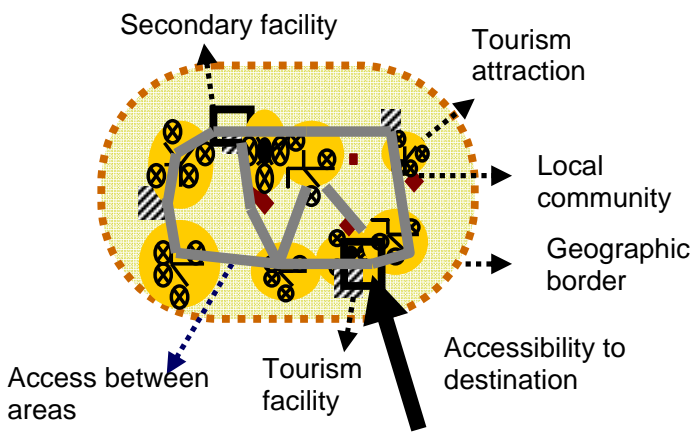

Figure 1: $\quad$ Tourist destination zone planning concept.

Destination generally is the component that attracts tourists traveling to a specific city. This component includes accommodation, catering, and activities/events. Main Journey is the component transporting travelers from other countries or regions into the designated city [6]. By understanding the demand; Urban Design Components (supply) can be categorized into "Primary Component", "Secondary Component", and "Transportation Component". The other components are the local community and experience that are the key elements that must be offered to visitors. These components are supplying the demand of Tourism Components. This is shown in the basic design model about Tourism Components which includes attractions, accommodation, local community and links by transportation component and being connected to other regions so that the city is accessible. From the perspective of tourism marketing, tourists have different choices of city potentially to visit. Branding the city involves promoting the uniqueness of a city which answers the question "Why should I visit your city?" [7]. Furthermore, in the design of a tourism city, the Urban Designer has the definite role of inserting uniqueness in a city. This uniqueness is the branding strategy for tourism marketing. This uniqueness creates the will of travel in tourists, and affects their decision to choose a desired destination. In this case, it is important to present the uniqueness by creating a distinctive setting in the city in question.

The Tourist Component for tourist destination planning is combined by several sources mentioned above and analysis can be visualized in figure 2 .

\subsection{Tourism and environment consciousness and emergence for social sustainability}

The term Recreational Business District (RBD) [8] is used to describe areas characterized by a distinctive array of pedestrian, tourist oriented retail 


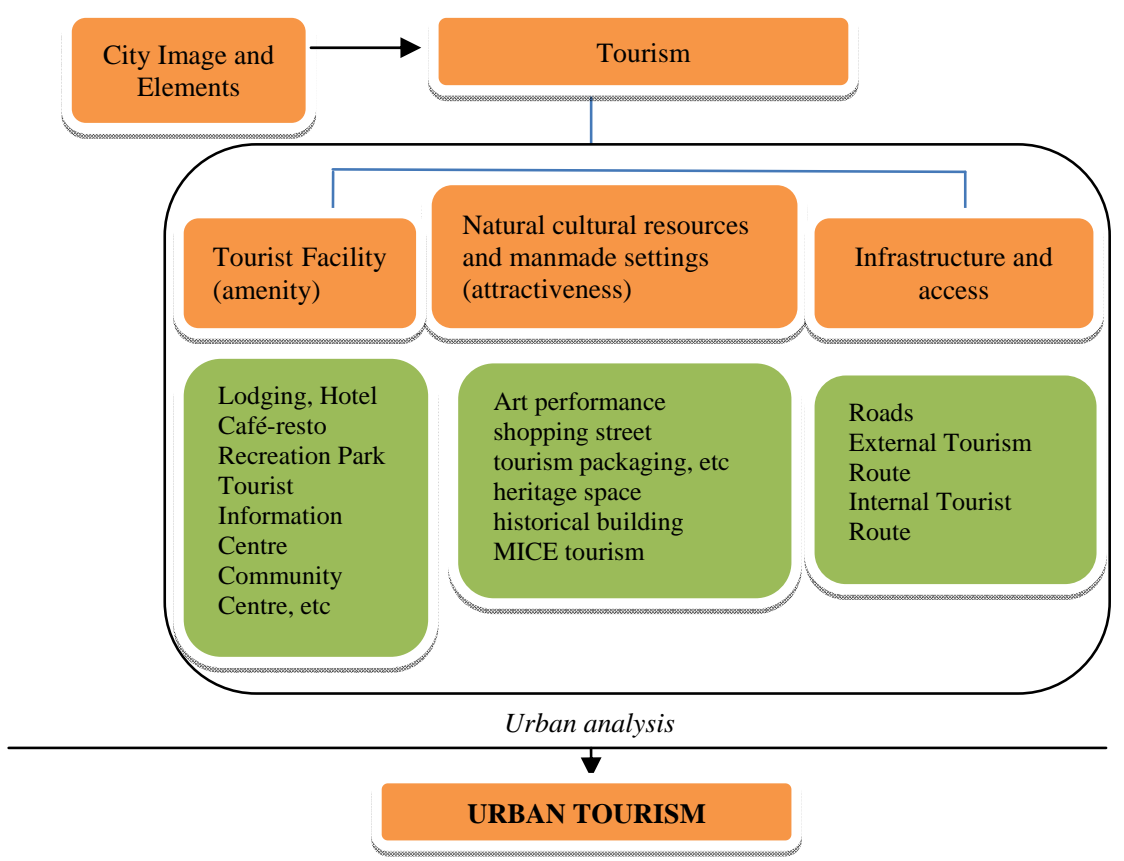

Figure 2: $\quad$ Framework of urban tourism.

facilities and which is separated spatially as well as functionally from the other business districts [9]. The response of this model is a Tourism Business District to focus more on the functions of these areas. This model describes how the main facility and tourist space are integrated and provides significant insight into the development and management of the tourist-historic city in urban tourism [10].

In the city area, the location of tourist services in relation to other aspects of urban form and function can reveal a great deal about the tourist city. It has been found that tourist facilities such as restaurants, hotels and retail outlets exhibit a number of spatial regulations in urban areas where proximity to a Central Business District (CBD), a residential neighborhood, and shopping malls are highly related with the success or failure of facilities. A widely dispersed and more concentrated in CBD with major transportation links and clustered facilities near the center of a city make it more accessible for people.

Urban areas are important tourist destinations and are major recipients of both citizen activity and tourism. At city planning, urban areas tend to provide places for people, for daily activity and special spaces for social interaction and recreational space that form part of social sustainability not considered to endanger the environment. Apart from the ecological, economical and cultural dimension, a key aspect of a sustainable city and sustainable tourism in a developed city is social sustainability. 


\section{Research objectives and methodology}

The aim of this study is critically identify, with comparisons, different city practices. This analysis can allow for knowledge sharing and use for further practices. In line with the study aim, several objectives are planned in this research: 1). To understand the phenomena of urban tourism, 2). To gain insight into the existing characteristic of the supply side of a city destination, including attractions, tourist amenities (physical facilities) and natural resources, from the point of view of urban tourism. In this research, a comprehensive literature review was conducted to find the information to gain the objectives of this research. Information was obtained from books, academic journals, and government and institutional reports.

\section{Kumamoto City tourism and sustainable strategy}

Kumamoto City in Japan is a representative example of a city that has a special service for urban tourism because of its attractiveness that has a natural specification and is heritage based. The strengths and the weaknesses of Kumamoto City need to be introduced or conducted to evolving its characteristic.

\subsection{Kumamoto City and environmental policy}

The comprehensive program/planning for Kumamoto City has prepared for Kumamoto to become a city designated by government ordinance. The planning of redesign divides the municipal office system, the transportation system, and the city center, having two goals: 1 ) the development of a city in which every resident feels safe and secure and that the city is a good place to work and raise families; 2) the development of the city as a destination - whether for tourism, business, education, or making a home. The Kumamoto Environmental Program that became the priority of the city includes: 1) Enhancement of the natural and build landscape; 2) Arts, Culture and Heritage; 3) Environmental Best Practices; 4) Community Participation and Empowerment; 5) Healthy Lifestyle; 6) Strategic Planning. A top priority for Kumamoto City is a long-term development based on the 6th Comprehensive Program 2009-2018, which was created after eliciting a wide range of opinions from city residents. The program aims to build a community in which residents can form and actively take part in rich and rewarding networks; to create a community full of pride and vitality; a community of security and generosity for generations to come. The other strength is that Kumamoto has a better health service compared to other cities in Japan.

\subsection{Kumamoto City tourism}

Tourism activity is not even considered as a leading and essential economic activity in Kumamoto compared to other cities in Kyushu, but Kumamoto has 

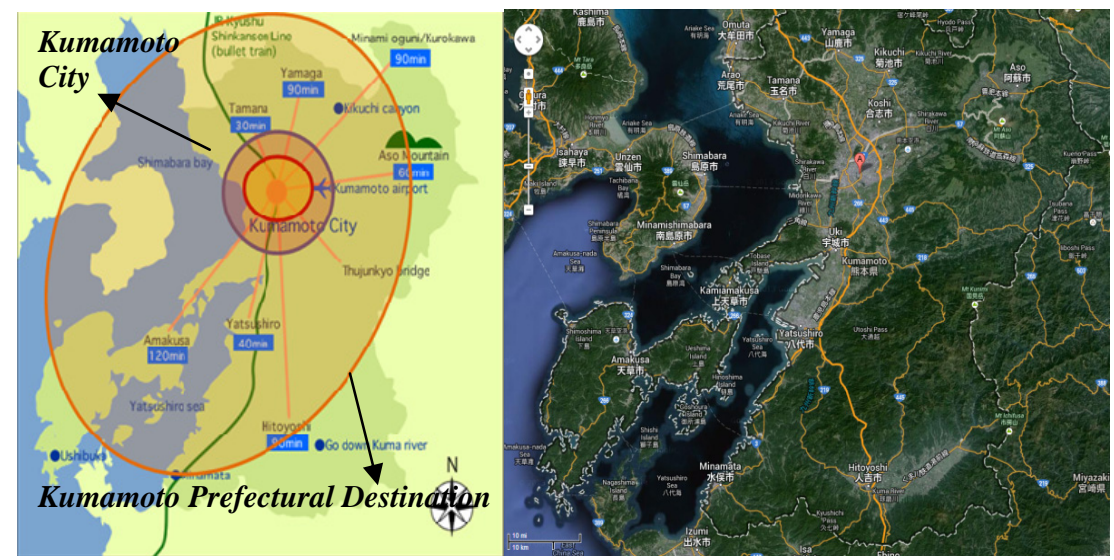
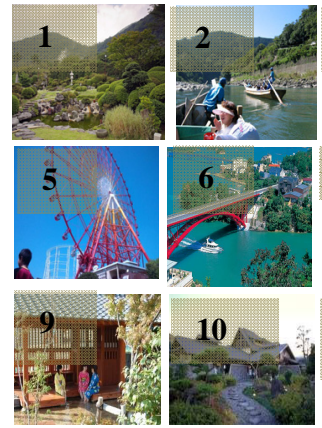
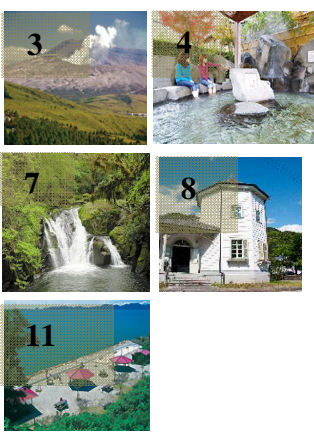

1. Unzen-Amakusa

2. Kumagawa river-Hitoyoshi

3. Aso Mountain

4. Yamaga Onsen

5. Greenland-Arao

6. Matsushima-KamiAmakusa

7. Kikuchi Gorge-Kikuci

8. Misumi Nishiko Park-Uki

City

9. Tamana Onsen-Tamana

10. Health and Welfare-Uto city

11. Yatsushiro boat floating

Figure 3: Kumamoto City attractions in the prefectural tourism linkage (map taken from [11]; pictures taken from [12]).

given great attention to tourism and public services. The several types that the city have are mentioned below:

1) Natural tourism - Kumamoto City is special city that has rich groundwater, which received the highest award of the UN Water for Life 2013 in Hague City, The Netherlands. The natural asset that can attract tourists to visit is spread over all districts in Kumamoto Shi, besides other towns in the Kumamoto Prefecture;

2) Archeological, historical and heritage tourism - the city has many historical shrines and has a landmark building - Kumamoto castle - in the downtown area. Traditional and old Japanese traditional houses, theaters and museums are spread along the city;

3) Leisure tourism and pop culture - the city offers contemporary art museums, theaters, cinemas, parks, gardens and game parks, also shopping centers in downtown areas); 
4) Business and conventional tourism - the city offers a commercial and industrial center, where businessmen travel across the country for trade or for spending holidays even in winter or summer also to attend commercial and industrial exhibitions;

5) Medical tourism - the city has many hospitals; public, university, military, and private which offer a lot of medical services to locals.

\subsubsection{Kumamoto City attraction in Kyushu linkage}

Kumamoto City is one of several main tourism zones in addition to other districts in the Kumamoto Prefecture. Main tourist attractions in the Kumamoto Prefecture are: Amakusa City with Onsen Amakusa National Park, beach and Gokyo Bridge; Arao with green land; Aso City with Aso Mountain; Hitoyoshi City with Hitoyoshi Onsen Hot Spring and Kumagawa River; Kamiamakusa City with Kamiamakusa Hot Spring; Matsushima Port; Kikuchi City with Kikuchi Gorge and Waifu Onsen; Minamata with Minamata Disease Museum; Tamana City with Unzen Tamana; Uto City with a health and welfare center, Yamaga City with Yamaga Unzen.

\subsubsection{Tourism data}

There were improvements in visitor numbers in 2011 caused by the development of Kyushu Shinkansen, the increasing quality of attractions and the newly developed attraction "Sakurano Baba" near Kumamoto Castle. The number of visitors in Kumamoto City and percentage, year by year, in 2010 and 2011 can be seen in table 1 .

Table 1: $\quad$ The number of visitors in Kumamoto.

\begin{tabular}{|l|c|c|c|c|}
\hline Tourist number & $\mathbf{2 0 1 1}$ & $\mathbf{2 0 1 0}$ & Improvement & Percentage \\
\hline Year & $5,468,000$ & $5,327,000$ & 141,000 & 2.65 \\
\hline Average visitor & $3,239,788$ & $3,230,955$ & 8,833 & 0.27 \\
\hline Stay & $2,228,212$ & $2,096,045$ & 132,167 & 6.31 \\
\hline Percentage in year & $40.75 \%$ & $39.35 \%$ & \multicolumn{2}{|c|}{1.4} \\
\hline Tourism cost & 621 & 600 & 21 & 3,5 \\
\hline
\end{tabular}

Tourism numbers, especially foreign tourists, in daily travel and over-night stays in Kumamoto City can be seen in table 2 below.

Table 2: $\quad$ Foreign tourists in Kumamoto City.

\begin{tabular}{|l|c|c|c|c|}
\hline Type of visitor & $\mathbf{2 0 1 1}$ & $\mathbf{2 0 1 0}$ & Improvements & Percentage \\
\hline Foreign visitation & 192,213 & 346,788 & 154,575 & 44,57 \\
\hline Foreign tourist stay & 40,191 & 54,072 & 13,881 & 25,67 \\
\hline
\end{tabular}




\subsubsection{Kumamoto tourism accessibility}

Transportation for people to go to Kumamoto from other cities can be reached by airplane, ferry and train. If reached from Japan, the easy access is from Haneda airport, Itami, Nagoya (Chubu) or Komaki. The availability of the shinkansen mode of transportation is also supported; to go to Kumamoto from Tokyo by JR Shinkansen or Shin Osaka to Hakata by JR Shinkansen Nozomi and Hikari and connecting limited express trains at Hakata by Ariake or Relay Tsubame. The other way is by using Shin-Osaka to Kumamoto by JR Shinkansen Sakura or Mizuho. On the destination level, the transportation to go to each attraction can be reached using local buses, trams and trains. The specialty of Kumamoto Castle as a Kumamoto landmark is provided by Loop Bus for travel to Kumamoto Castle and the surrounding area.

\subsubsection{Kumamoto City tourist attractions}

Kumamoto City has several tourist attractions including historical and cultural sources - natural - and also man-made attractions like cultural events, a shopping centre, park and other spots in the city. There are several tourist spots in Kumamoto city; the most attractive places being Kumamoto Castle, Suizenji Jojuen Park, Kumamoto Prefectural Museum and Traditional Craft Museum.

Based on Kumamoto International Bureau, the most visited places in Kumamoto city are shown in table 3.

Table 3: $\quad$ The most visited attractions in Kumamoto City.

\begin{tabular}{|l|c|c|c|c|}
\hline Name of Attraction & $\mathbf{2 0 1 1}$ & H22 & Improvement & Percentage \\
\hline Castle & $1,561,268$ & $1,552,173$ & 9,095 & $0.59 \%$ \\
\hline Jou sai en & $1,245,791$ & no data & no data & no data \\
\hline Suizenji & 305,159 & 275,500 & 29,659 & $10.77 \%$ \\
\hline Kumamoto Museum & 147,070 & 82,131 & 64,939 & $79.06 \%$ \\
\hline
\end{tabular}

Several main tourism attractions in Kumamoto City can be seen in the Kumamoto Tourism map (see figure 4).

\subsubsection{Kumamoto tourism facility}

Kumamoto City has several places for accommodation that support tourism activity. The most important accommodation place in the city is a hotel that can be used as a facility for visitors or tourists; both international and domestic. The main hotels, such as Hokke Club, Kumamoto Tokyu Inn Hotel, Hotel Sun Route Kumamoto, Kumamoto Hotel Castle, Kumamoto Kotsu Center Hotel, Ana Hotel Kumamoto New Sky, Higoji and Maruko Hotel are spread around Kumamoto Downtown. 


\subsubsection{Kumamoto City tourism and sustainability}

Sustainable tourism, defined as tourism that takes full account of its current and future economic, social and environmental impacts, addresses the needs of visitors, industry, the environment and host communities. Meanwhile, the concept of a sustainable tourism management framework is divided into three important aspects: 1) quality of life (involvement of local communities, improving the economy and businesses, minimizing the social impact); 2) quality of experience (the uniqueness, imagination and interpretation and curiosity); 3) quality of resources (nature and management cultural resources preservation) [11].
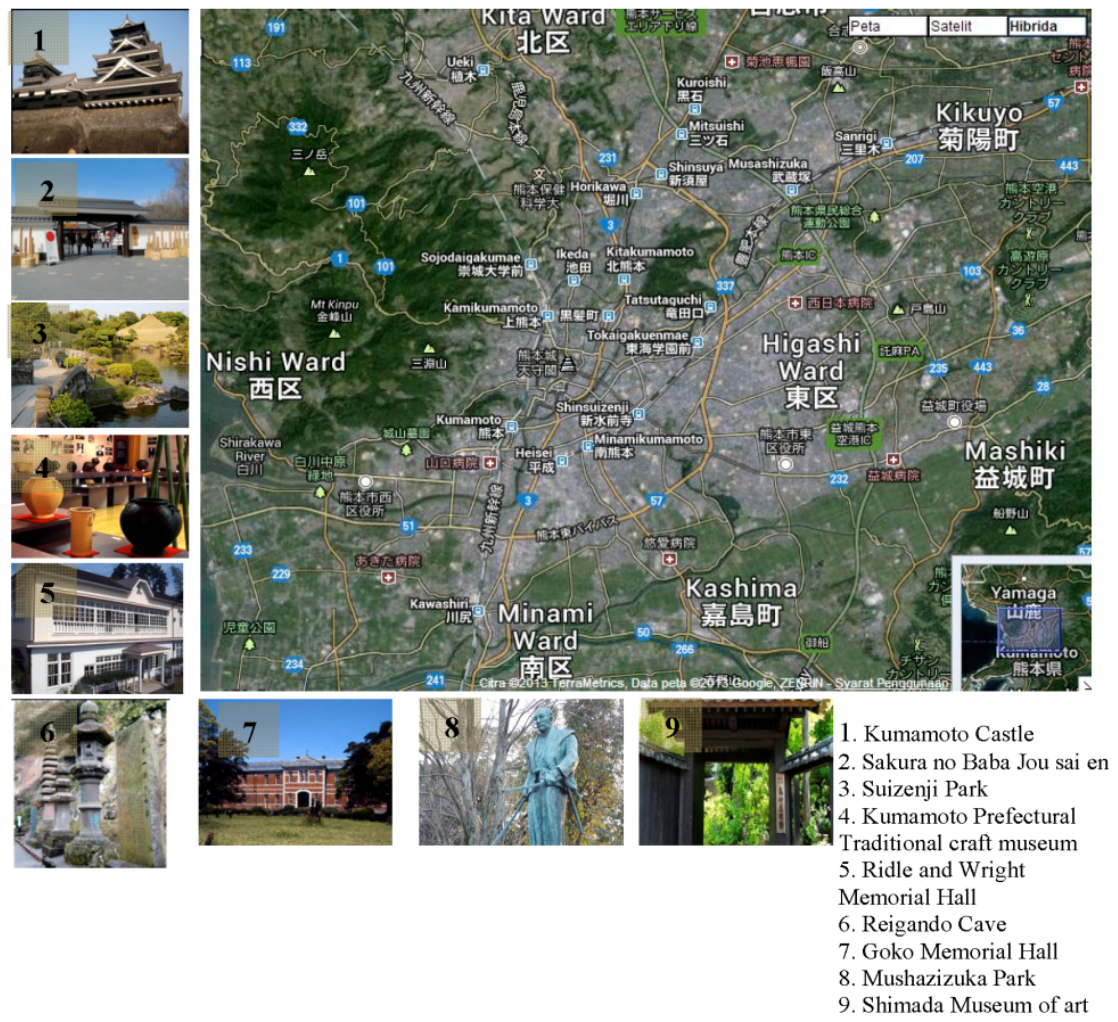

Figure 4: $\quad$ Kumamoto city tourist attraction (map taken from [13]; pictures taken from [14].)

Regarding this point of view, Kumamoto urban areas offer social, cultural, physical and aesthetic aspects where both citizen and tourist activity can be accommodated. This complex urban space shapes experience as visitor can do and interact with, in one destination. As tourism space can provide "places" for civil interaction, for healing for a while from rapid activity and escape from daily 
life in a weekend at the tourist destination. Tourism from both a supply and demand perspective is not dispersed throughout the city but is more concentrated to a small geographic area. The visitor uses urban attractions and infrastructure, and economic aspects, unrelated with tourism but connected. This is fundamental to understanding the phenomenon of urban tourism and the characteristic in the city. In Kumamoto City, the Tourist Business District of the city is located in the center of city (Kumamoto Downtown) where the Central Business District is connected and integrated with core attractions and essential services (infrastructure).

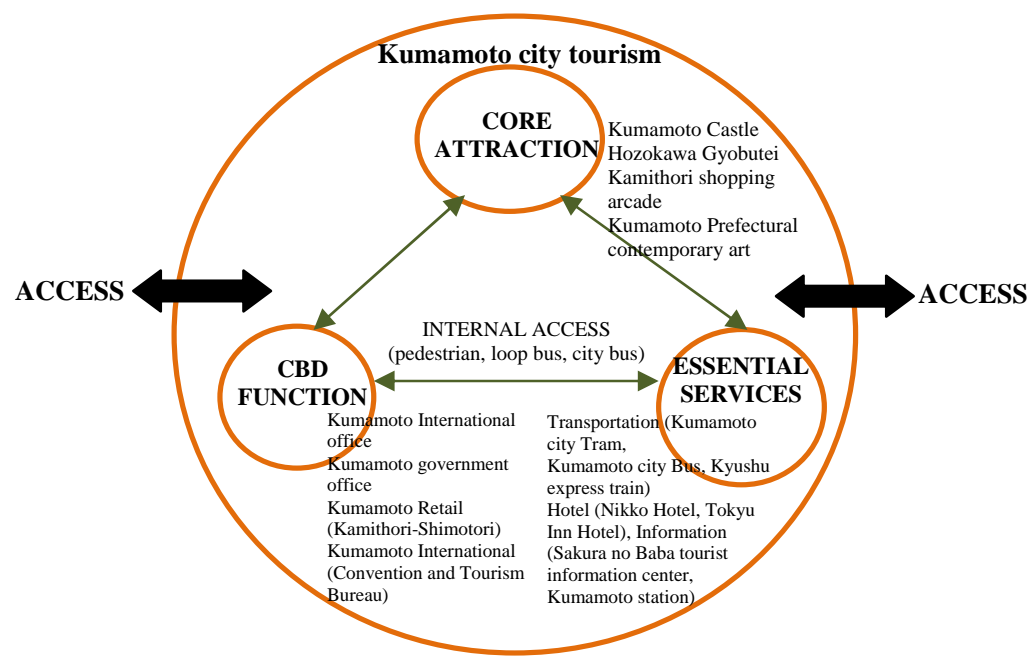

Figure 5: $\quad$ Kumamoto City Tourism Business District model.

Kumamoto urban areas are important tourist destinations and major recipients of both citizen activity and tourism. They provide places for people to do daily activity, interact socially and have recreational space. Compared with Japan cities that have a long history of tourism, such as a city like Kyoto, Kumamoto has both weaknesses and strengths. Even the heritage area in Kumamoto city is not as extensive as in Kyoto. Kumamoto has a rich and better quality of groundwater, good healthcare and welfare center and has many natural attractions. A European city like Zurich that has a similar size and topography with Kumamoto city has a good theme of city and branding and a good quality of life with many educational facilities but has a high cost based life. Kumamoto still is a small size compared to other global cities but it offers a good quality of life for its citizens and tries to develop a good image as one of the tourism cities in Japan. 


\section{Conclusion}

Urban tourism as a new different approach for enhancing urban well being is important regarding a set of objectives in social sustainability that is an important aspect within the city. Whilst various urban problems/environmental degradation in Japan have existed, the aim to enhance the community welfare through economy development and at the same time with social development by urban tourism is one approach that can enhance other aspects of sustainability.

Achieving sustainable urban tourism in a city context needs to work with and respond to market conditions, demographic changes and political challenges. Despite the enormity of the challenges, urban tourism planning can play a significant role in the mix of public and private actions toward the goal of sustainability. In the last discussion, the important aspects that urban tourism should provide are: providing places for tourists to explore the city, provide places that assist the tourist to compress their experience of the city, put the tourist into a state of mind that reflects their desires as a tourist within a city, enabling the visitor to connect with the people of the city in a setting where the needs and mind states of both tourists and residents are compatible; enabling the tourist to develop a better understanding of the city, its people and its history; enabling the tourist to experience a more distinctive sense of place than is afforded by an 'internationalized' city centre; and providing an environment where the tourist has more freedom to wander and explore. Another key success of urban planning for a tourism city is to offer a distinctive experience to tourist satisfaction with tourism facilities without affecting the environment. Conversely, a distinctive quality of a city does not ensure the tourism industry success without an adequate supply of tourism components. These tourism facilities supply for tourists' basic needs such as shelter, food and mobility which are the key contributions to an overall satisfactory and distinctive experience. In conclusion, affordable urban design and planning are the key role in creating unique supplies for urban tourism to offer people experience.

\section{References}

[1] Hall, C. M. Tourism Planning: Policies, Processes and Relationships. 2nd Edition. Harlow: Pearson/Prentice Hall, 2008.

[2] Jadon, S.S. Basic Concept of Urban Design: A Research Review, ITPI Journal 4: 1, p. 70, 2007.

[3] Lynch K. The image of the city. The MIT Press, Cambridge, in S.S Jadon, Basic Concept of Urban Design: A Research Review, ITPI Journal 4: 1, pp.70-72, 2007.

[4] Davidson and Maitland. Tourist Destination. London: Hodder and Stoughton, 1997.

[5] Gunn, C. Tourism Planning: Basics, Concepts and Cases. Washington: Francis and Taylor. 1993

[6] Laws, E. Tourism Marketing: Service and Quality Management Perspectives. London: Continuum, 1991. 
[7] Kolb, B. M. Tourism Marketing for Cities and Towns: Using Branding and Events to Attract Tourists. Oxford: Elsevier, 2006.

[8] Stansfield, C. A. and Rickert, J.E. The recreational business district. Journal of Leisure Research 2 (4) 213-225, 1970.

[9] Getz, D. Planning for Tourism Business District. Annals of Tourism Research, 20 (3), 583-600, 1993.

[10] Ashworth, G.J and Tunbridge, J.E. The Tourist Historic City. Built Environment, in D.J. Timothy \&. G. Wall, Accommodation in Asian Historic City, The Journal of Tourism Study, Volume 6 No.2, 64-65, 1995.

[11] Kumamoto prefecture map, https://maps.google.com/maps/ms?ie= $\underline{\text { UTF8\&oe }=\text { UTF8\&msa }=0 \& m s i d=108869558573294390055.00048 a b a 104}$ 6eec2ff2d5

[12] Kumamoto Prefecture. http://www.japan-guide.com/list/e1244.html

[13] Kumamoto google map. http://www.satellitecitymaps.com/asia-map /japan-map/kumamoto-ken-map/kumamoto-map/

[14] Sightseeing spot in Kumamoto city. http://www.manyoukumamoto.jp/contents.cfm?id=244

[15] McIntyre, G. Sustainable Tourism Development: Guide for Local Planners. Madrid : World Tourism Organization, 1993.

[16] Kumamoto Tourism Bureau. Kumamoto Tourism Statistic, Japan, Kumamoto Tourism Cultural Exchange Bureau Tourism Promotion Division, 2011. 